\title{
Posterior pericardial approach for ascending-to-descending aortic bypass for anastomotic leak of infected interpositional graft
}

\author{
Masakazu Nakao, MD, a See Lim Lim, MBBS, FRCS, FAMS, ${ }^{a}$ Kiang Hiong Tay, MBBS, FRCR, FAMS, ${ }^{\text {b }}$ and \\ Yeow Leng Chua, MBBS, FRCS, FAMS, ${ }^{a}$ Singapore
}

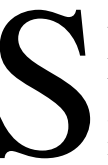

urgical repair is standard treatment for aortic transection. Management of infective complications after aortic grafting is less well defined. We describe this management in a patient with polytrauma and report ascendingto-descending aortic bypass in this setting.

\section{Clinical Summary}

A 25-year-old male car driver sustained multiple injuries in a road traffic crash, including hepatic laceration, aortic transection, and right humeral and femoral fractures. He underwent emergency laparotomy and partial hepatectomy. A subsequent aortogram revealed a pseudoaneurysm distal to the left subclavian artery. Repair of the transected aorta was performed with the proximal descending aorta replaced with an 18-mm woven Dacron graft through a left thoracotomy.

Recovery was complicated by methicillin-resistant Staphylococcus aureus (MRSA) infection of a large sacral sore, which required a rotation flap, and bilateral MRSA empyema, which was managed with Cope loop drainage and 6 months of intravenous vancomycin.

Three years later, the patient returned with hemoptysis. Computed tomographic scan and aortogram demonstrated leakage from the distal end of the aortic graft resulting in a pseudoaneurysm and an aortobronchial fistula. Endoluminal stenting with a $22 \mathrm{~mm} \times$ $131 \mathrm{~mm}$ Talent LPS stent graft (Medtronic AVE, Santa Rosa, Calif) was performed with successful occlusion of the leak. MRSA septicemia developed in the patient after the procedure, and he was treated with intravenous vancomycin and subsequently with intramuscular teicoplanin.

Two years later, the patient returned with a 2-month history of hemoptysis. Computed tomographic scan of the thorax was suggestive of a recurrent leak, which was confirmed on aortogram (Figure 1).

Emergency extra-anatomic ascending aorta-to-descending aorta bypass was performed with exclusion of the proximal descending thoracic aorta from which the leak arose. This was

\footnotetext{
From the Department of Cardiothoracic Surgery, National Heart Center, and the Department of Interventional Radiology, Singapore General Hospital, ${ }^{\mathrm{b}}$ Singapore.

Received for publication April 28, 2005; accepted for publication June 7, 2005 .

Address for reprints: Chua Yeow Leng, Mistri Wing, 17 Third Hospital Ave, Singapore 168752 (E-mail: CHUA_Yeow_Leng@nhc.com.sg).

J Thorac Cardiovasc Surg 2005;130:946-7

$0022-5223 / \$ 30.00$

Copyright $\odot 2005$ by The American Association for Thoracic Surgery

doi:10.1016/j.jtcvs.2005.06.002
}

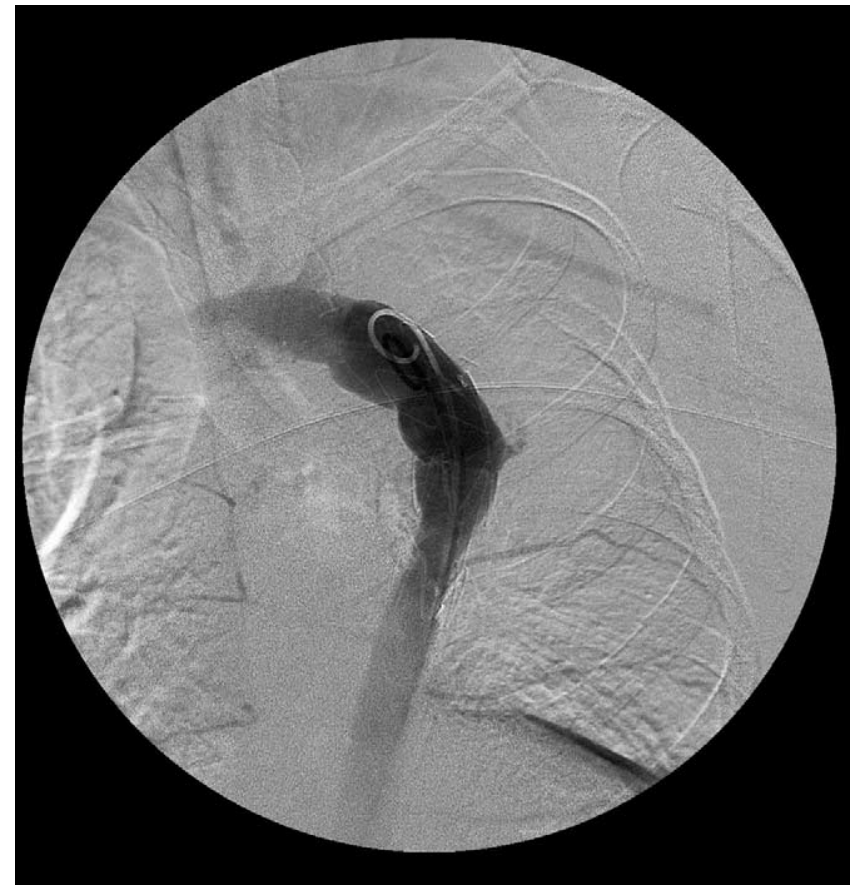

Figure 1. Preoperative aortogram showing recurrent leak.

performed through a median sternotomy on full cardiopulmonary bypass via ascending aortic and right atrial cannulation. With the empty heart displaced superiorly, the distal descending aorta was accessed through a longitudinal incision in the posterior pericardium. A 16-mm woven Dacron graft was anastomosed to the distal descending thoracic aorta with a side-biting clamp. The graft was tracked posterior to the inferior vena cava and anastomosed to the right lateral aspect of the ascending aorta (Figure 2). The descending aorta between the left subclavian artery and the new distal anastomosis was excluded. At the end of surgery, the heart was edematous; the chest was closed 5 days later. Hemoptysis settled, and the patient made a satisfactory recovery.

In view of the patient's life-threatening complications from MRSA infection to the prosthetic grafts, he is on lifelong antiMRSA treatment. He has remained well for the past 2 years.

\section{Comment}

Aortic transection occurs in $11.5 \%$ of road traffic crashes ${ }^{1}$ and has a mortality rate of $80 \%$ to $85 \%$ at the scene. Of the $10 \%$ to $15 \%$ of patients who reach the hospital alive, $20 \%$ will die of aortic rupture. These patients require emergency repair of the thoracic aorta, but the perioperative mortality rate is as high as $30 \%{ }^{2}$ 


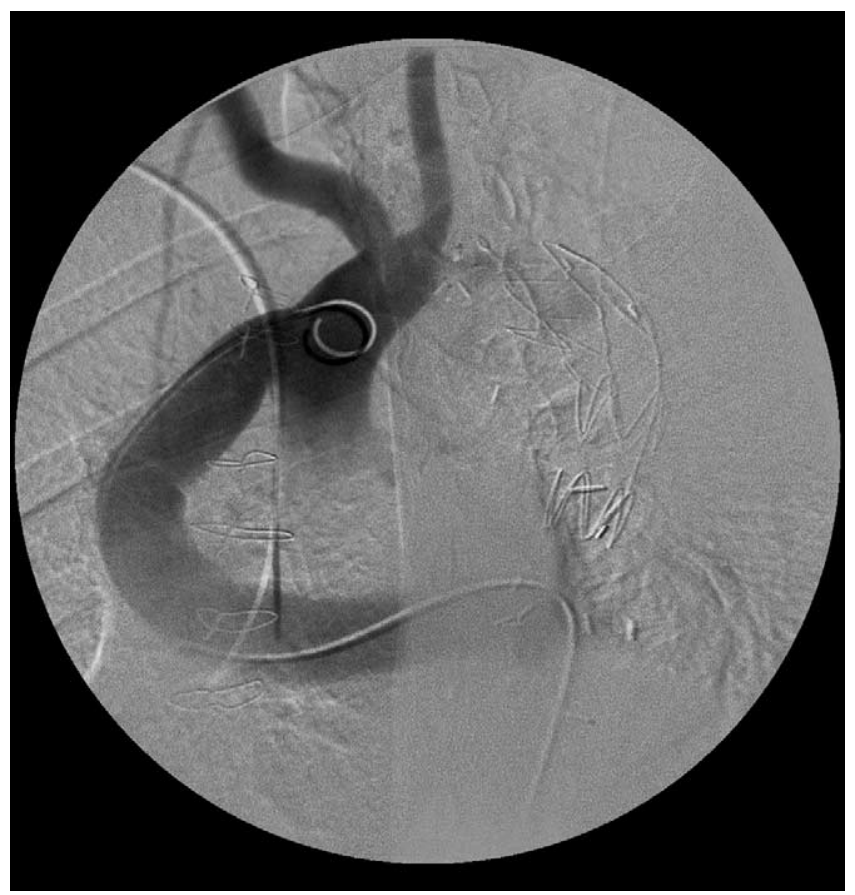

Figure 2. Postoperative aortogram showing extra-anatomic ascending aorta-to-descending aorta bypass and occluded descending aorta.

The patient reported here underwent interposition of the aorta after laparotomy and hepatectomy, but MRSA infection subsequently developed in both pleural spaces. Despite drainage and 6 months of antibiotic treatment, an anastomotic leak occurred 3 years later. Percutaneous endoluminal stenting was performed.

Stent grafting to an infected portion of the aorta is controversial; however, the alternative open surgical approach carries a high mortality rate. Piciche and colleagues ${ }^{3}$ reported no deaths after endoluminal stenting for aortobronchial fistula as opposed to $16 \%$ with surgical repair.
The hemoptysis promptly resolved after percutaneous stenting but recurred after a further 2-year interval. An endoleak had developed at the site of the previous leak, so repeat stenting was not considered.

When deciding on a surgical approach, we had to take into consideration likely residual MRSA infection in the left pleural cavity. As such, we excluded the entire infected field and bypassed the ascending aorta to the descending aorta through a median sternotomy. Although this approach placed the graft in the pericardial cavity, out of direct contact with the infected area, it also precluded simultaneous explantation of the stent. Regardless, with the aortic end of the aortobronchial fistula excluded, the lifethreatening hemoptysis had been addressed and no further surgery in the infected field was immediately necessary. This procedure was initially described by Vijayanagar and colleagues ${ }^{4}$ for coarctation of aorta. Izhar and colleagues ${ }^{5}$ reported a series of 17 cases with a variety of aortic conditions including coarctation of the aorta, Takayasu's aortitis, and complex descending aortic arch aneurysm. To our knowledge this is the first report of extraanatomic ascending aorta-to-descending aorta bypass for an infective leak from a previous interposition graft for aortic transection. The advantages of this approach are avoiding extensive pleural dissection in potentially infected areas and achieving exclusion and bypass through a single median sternotomy as apposed to a bilateral axillofemoral bypass.

\section{References}

1. Williams JS, Graff JA, Uku JM, Steinig JP. Aortic injury in vehicular trauma. Ann Thorac Surg. 1994;57:726-30.

2. Fabian TC, Richardson JD, Croce MA. Prospective study of blunt aortic injury: multicenter trial of the American Association for the Surgery of Trauma. J Trauma. 1997;42:374-83.

3. Piciche M, De Paulis R, Fabbri A, Chiariello L. Postoperative aortic fistula into the airways: etiology, pathogenesis, presentation, diagnosis, and management. Ann Thorac Surg. 2003;75:1998-2006.

4. Vijayanagar R, Natarajan P, Eckstein PF, Bognolo DA, Toole JC. Aortic valvular insufficiency and postductal aortic coarctation in the adult: combined surgical management through median sternotomy: a new surgical approach. J Thorac Cardiovasc Surg. 1980;79:266-8.

5. Izhar U, Schaff HV, Mullany CJ, Daly RC, Orszulak TA. Posterior pericardial approach for ascending aorta-to-descending aorta bypass through a median sternotomy. Ann Thorac Surg. 2000;70:31-7. 